\title{
Prospective audit of upper gastrointestinal endoscopy in two regions of England: safety, staffing, and sedation methods
}

\author{
M A Quine, G D Bell, R F McCloy, J E Charlton, H B Devlin, A Hopkins
}

\begin{abstract}
A prospective audit of upper gastrointestinal endoscopy in 36 hospitals across two regions provided data from 14149 gastroscopies of which 1113 procedures were therapeutic and 13036 were diagnostic. Most patients received gastroscopy under intravenous sedation; midazolam was the preferred agent in the North West and diazepam was preferred in East Anglia. Mean doses of each agent used were $5.7 \mathrm{mg}$ and $13.8 \mathrm{mg}$ respectively, although there was a wide distribution of doses reported. Only half of the patients endoscoped had some form of intravenous access in situ and few were supplied with supplementary oxygen. The death rate from this study for diagnostic endoscopy was 1 in 2000 and the morbidity rate was 1 in 200; cardiorespiratory complications were the most prominent in this group and there was a strong relation between the lack of monitoring and use of high dose benzodiazepines and the occurrence of adverse outcomes. In particular there was a link between the use of local anaesthetic sprays and the development of pneumonia after gastroscopy $(p<0.001)$. Twenty perforations occurred out of a total of 774 dilatations of which eight patients died (death rate 1 in 100). A number of units were found to have staffing problems, to be lacking in basic facilities, and to have poor or virtually non-existent recovery areas. In addition, a number of junior endoscopists were performing endoscopy unsupervised and with minimal training.

(Gut 1995; 36: 462-467)
\end{abstract}

Keywords: endoscopy, anaesthesia.

Despite the assumption by many doctors that upper gastrointestinal endoscopy has become both safe and suitable for all patients, recent reports continue to show that complications with upper gastrointestinal endoscopy are occurring at a comparatively consistent rate. ${ }^{12}$ As the number of elderly and high risk patients subjected to the procedure increases, the number of cardiopulmonary complications rises in parallel. ${ }^{3}$ Sedation techniques are probably responsible for some of the medical complications seen, but operator inexperience, and lack of monitoring may also be important. This audit has been designed to investigate how often problems occur at the time of upper gastrointestinal endoscopy and for a 30 day period after the procedure, and to explore common variables in endoscopy practice when such complications occur. The audit has included all flexible diagnostic and therapeutic fibreoptic upper gastrointestinal endoscopy and has excluded rigid oesophagoscopy and endoscopic retrograde cholangiopancreatography. It is hoped that the findings of this study will encourage endoscopists to examine their own practices and thus reduce complication rates associated with endoscopy.

\section{Methods}

The project began with the researcher (MAQ) visiting all units, endoscopists, and endoscopy assistants throughout the North West region and East Anglia. For a four month period, forms completed by the endoscopist at the time of the gastroscopy recorded: where it was performed; the experience of the endoscopist; the reason for endoscopy; the nursing level; sedation and monitoring details; and the outcome. One of the important aims of the project was to assess the death and morbidity rates at the time of and for 30 days after endoscopy. When the procedures had been performed, the patients' notes were flagged requesting that any subsequent adverse events be reported to the endoscopy sister (who acted as a coordinator for the project at each site). Similarly, letters were filed in the patients' notes and sent to the patients' general practitioners explaining the purpose of the audit. All records relating to hospitals and doctors taking part in the study were strictly coded so that it would not be possible to trace any adverse outcome to an individual hospital or doctor.

Each unit was contacted on a three weekly basis to enquire about any problems with the audit including the completion of forms. The data were validated at the end of the study. Seven per cent of the completed forms were checked against the information in the hospital 
TABLE I Mean dose of diazepam used against age

\begin{tabular}{lll}
\hline Age $(y)$ & Dose $(\mathrm{mg})$ & $+1-1$ SD $(\mathrm{mg})$ \\
\hline$<20$ & $18 \cdot 4$ & $6 \cdot 6$ \\
$20-29$ & $17 \cdot 4$ & $6 \cdot 9$ \\
$30-39$ & $16 \cdot 6$ & $6 \cdot 9$ \\
$40-49$ & $16 \cdot 4$ & $6 \cdot 6$ \\
$50-59$ & $15 \cdot 3$ & $6 \cdot 0$ \\
$60-69$ & $13 \cdot 0$ & $5 \cdot 3$ \\
$70-79$ & $10 \cdot 4$ & $5 \cdot 9$ \\
$80-89$ & $8 \cdot 5$ & $4 \cdot 3$ \\
$>89$ & $8 \cdot 6$ & $6 \cdot 1$ \\
\hline
\end{tabular}

notes showing a $95 \%$ accuracy rate of form completion. In addition, the total number of endoscopies performed by each unit was compared with the audit's total: compliance with the study was $99.9 \%$ on the endoscopy unit, whereas in theatres the comparative figure was $84 \cdot 6 \%$.

(Full details of the method and the validation process are available from the principal author.)

\section{Results}

Thirty six of 39 hospitals took part in the study. A total number of 383 doctors participated, including 148 consultants (only 34\% of these were members of the British Society of Gastroenterology, BSG).

In the four month period from FebruaryJune 1991 East Anglia performed 3956 upper gastrointestinal endoscopies (an estimated 5.76 gastroscopies $/ 1000 / y$ ) and in the four month period from April-August 1991 the North West carried out 10193 examinations (8.8/1000/y). The total number of procedures performed was 14149 of which 13036 (92\%), were diagnostic and the remaining $8 \%$ were therapeutic.

Twenty seven per cent (3813) of the procedures were not carried out on designated endoscopy units. Twenty one per cent of all gastroscopies performed in East Anglia and $25 \%$ in the North West were conducted with either one nurse in attendance or with two or more unqualified nurses ( $\mathrm{C}$ grade or below).

Thirty per cent of all patients undergoing endoscopy were over 70 years of age; only half of the patients were categorised as ASA 1 (The American Society of Anethesiologists classification of physical status), while over $10 \%$ of patients fell into groups ASA 3-5 (that is, groups of high risk).

In East Anglia and the North West, (a) $4 \cdot 4 \%$ (173) and $2 \cdot 3 \%$ (238) respectively of all endoscopies were performed under general anaesthesia; (b) $2 \cdot 3 \%$ (91) and $0 \cdot 4 \%$ (45) were performed without sedation or local anaesthetic; (c) $7 \cdot 1 \%$ (282) and $12 \cdot 6 \%$ (1291) were performed with local anaesthetic alone; and (d) $86 \% \quad(3405)$ and $84 \% \quad(8593)$ were performed with some form of intravenous sedation with or without local anaesthetic. Diazepam was the preferred intravenous sedative in East Anglia (used in 59\% of all patients sedated), whereas more endoscopists favoured midazolam in the North West (used in $57 \%$ of all patients sedated). The mean dose of diazepam used for sedation in the two regions was $13.5 \mathrm{mg}$ (East Anglia) and 14.0 mg (North West) and for midazolam the mean dose was $5.7 \mathrm{mg}$ in both regions. The distribution of dosages used in both regions was wide, however, so that sole consideration of the mean doses used is unhelpful, without reference to patient age or ASA grouping. The maximum doses of diazepam and midazolam used were $50 \mathrm{mg}$ and $30 \mathrm{mg}$, respectively. The variation in dose given against age shows a decrease with advancing age over 70 years (Tables I and II) but for each age group the dose given varied. A local anaesthetic spray was used much more frequently in the North West $(76.8 \%$ compared with $40 \cdot 5 \%$ ).

Most patients sedated with a combination of an opioid and a benzodiazepine were undergoing simple diagnostic rather than therapeutic endoscopy ( $78 \%$, East Anglia, $n=425 ; 58 \%$, North West, $n=171)$. Although the average dose of pethidine was almost $50 \mathrm{mg}$ in both regions, overall there was an increase in the mean dose of benzodiazepine given when used in combination, compared with when the benzodiazepine was used alone.

Hyoscine 22 was largely the anticholinergic of choice, though most procedures were performed without the use of hyoscine 22 or atropine. Intravenous atropine $(0.6 \mathrm{mg})$ was used much more frequently in the North West ( $11.2 \%$ compared with $0.3 \%$ in East Anglia), while conversely more endoscopists used hyoscine 22 (dose range 10-40 mg) in East Anglia (29\% compared with $20.6 \%$ in the North West). Four hundred and twenty eight patients $(4 \cdot 2 \%)$ in the North West received flumazenil after sedation to reverse the effects of benzodiazepines compared with $20(0.5 \%)$ in East Anglia. Whereas $22 \%$ of the doses used in East Anglia were used in an emergency to reverse benzodiazepine induced respiratory depression, the corresponding figure for the North West was $3 \cdot 6 \%$. Much of the nonurgent use of flumazenil in the North West (412 patients) reversed residual sedation when adequate staffing levels and recovery areas could not be provided.

Endoscopists differed widely in their use of continuous intravenous access, pulse oximetry, and supplementary oxygen. More inpatients than outpatients had intravenous access (59.6\% and $40.2 \%$ respectively). Intravenous access was used rarely in patients who were endoscoped without sedation $(5 \cdot 6 \%)$. Overall, cannulas were used in $12 \cdot 8 \%$ of cases and a butterfly (winged needle) in $30 \% ; 40 \%$ of patients were endoscoped with the aid of pulse oximetry and only $12.5 \%$ were given oxygen supplementation throughout. Of particular concern are the figures relating to ASA groups 3-5 - that is, 'high risk patients': only $15 \%$ of these patients (sedated) in the North West

TABLE II Mean dose of midazolam used against age

\begin{tabular}{lll}
\hline Age $(y)$ & Dose $(\mathrm{mg})$ & $+1-1$ SD $(\mathrm{mg})$ \\
\hline$<20$ & $7 \cdot 0$ & $2 \cdot 9$ \\
$20-29$ & $7 \cdot 2$ & $3 \cdot 1$ \\
$30-39$ & $6 \cdot 8$ & $2 \cdot 7$ \\
$40-49$ & $6 \cdot 8$ & $2 \cdot 7$ \\
$50-59$ & $6 \cdot 0$ & $2 \cdot 5$ \\
$60-69$ & $5 \cdot 5$ & $2 \cdot 1$ \\
$70-79$ & $4 \cdot 7$ & $1 \cdot 8$ \\
$80-89$ & $4 \cdot 1$ & $1 \cdot 8$ \\
$>89$ & $3 \cdot 1$ & $1 \cdot 3$ \\
\hline
\end{tabular}


TABLE III Number of endoscopy related cardiopulmonary deaths, arrests, and collapses at the time of endoscopy

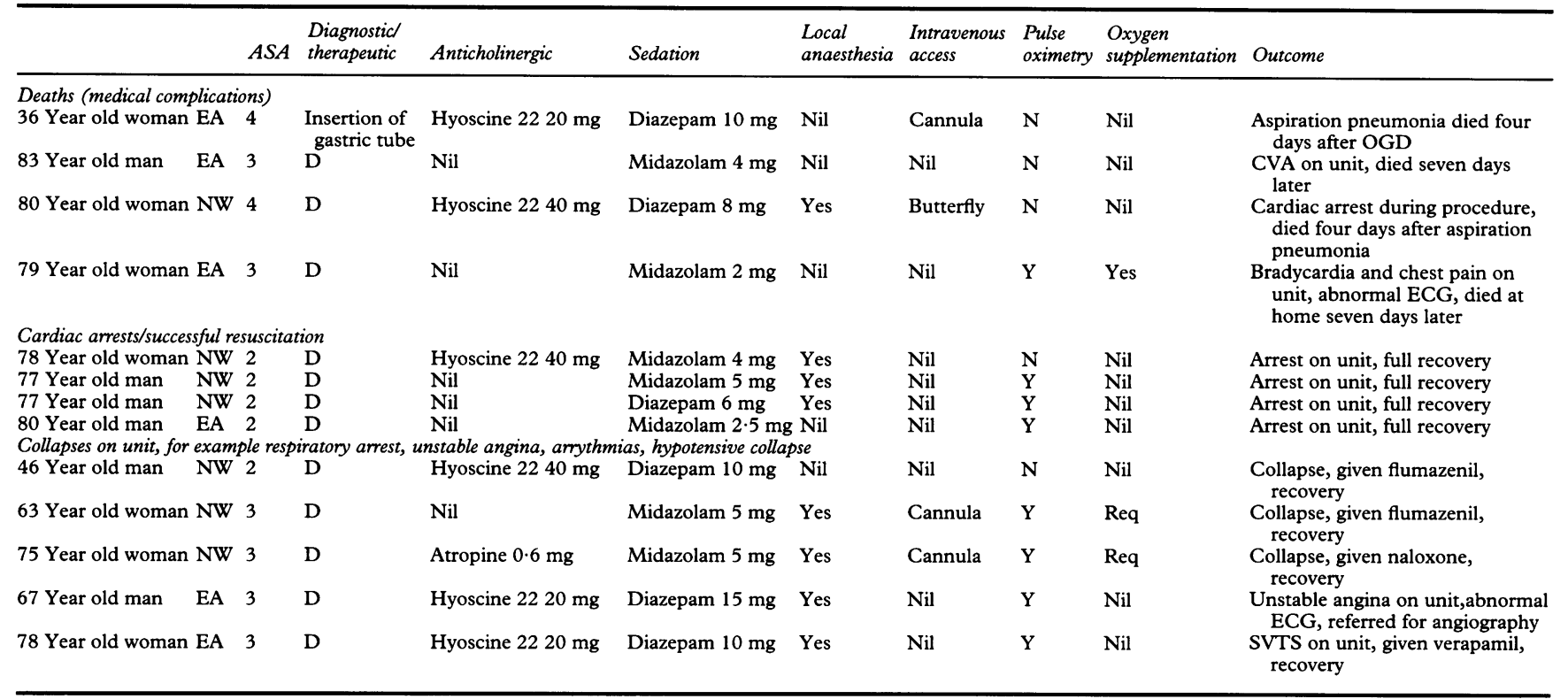

OGD=oesophagogastroduodenoscopy, CVA= cardiovascular accident.

were given oxygen during the procedure, and only $37 \%$ had continuous intravenous access.

A variety of complications occurring within 30 days of endoscopy were reported to the local coordinators, these are shown in Tables III and IV. At least four deaths resulted from cardiorespiratory complications after diagnostic gastroscopy. One further death was the result of extensive haemorrhage from a biopsied oesophageal ulcer in a patient with an abnormal clotting screen, and another death followed perforation at diagnostic gastroscopy. A final patient who had diagnostic endoscopy despite coexistent severe emphysema and chronic bronchitis, died from extensive mediastinal emphysema after rupture of bullae, which may have been caused by pressure changes occurring in the chest during the examination. Therefore seven deaths were thought to have been directly related to diagnostic gastroscopy, seven of 13036 , which would infer a death ratio of approximately 1 in 2000 for diagnostic gastroscopy.

Other complications occurred that may have been related to the performance of the procedure. These were 11 cases of pneumonia, six cerebrovascular accidents, and 19 myocardial

TABLE IV Morbidity and mortality within 30 days after endoscopy

\begin{tabular}{|c|c|}
\hline $\begin{array}{l}\text { Medical complications } \\
\text { Cardiorespiratory distress on the unit (requiring active treatment eg, } \\
\text { flumazenil) } \\
\text { Pneumonia (? related) } \\
\text { Pulmonary emboli } \\
\text { Myocardial infarction } \\
\text { Cerebrovascular accident } \\
\text { Gastrointestinal bleeding after OGD } \\
\text { All other deaths ( } 42 / 50 \text { cancer related) }\end{array}$ & $\begin{array}{l}31 \\
11 \text { ( } 8 \text { died) } \\
3 \text { ( } 3 \text { died }) \\
19 \text { ( } 14 \text { died }) \\
6 \text { (4 died) } \\
22 \text { ( } 14 \text { died) } \\
50 \text { Deaths }\end{array}$ \\
\hline $\begin{array}{l}\text { Perforations } \\
\text { Perforation after diagnostic procedure }(n=13036) \\
\text { Rupture of emphysematous bullae during diagnostic procedure }(n=13036) \\
\text { Perforation after dilatation of malignant strictures (including intubation) } \\
\quad(n=220) \\
\text { Perforation after dilatation of benign strictures }(n=554) \\
\text { Perforated duodenal ulcer after injection for bleeding duodenal ulcer } \\
\quad(n=22)\end{array}$ & $\begin{array}{c}6 \text { (1 died) } \\
1 \text { (died) } \\
14 \text { (5 died) } \\
6 \text { (3 died) }\end{array}$ \\
\hline Total no of deaths & $\begin{array}{l}104 \text { Deaths within } \\
30 \text { days }\end{array}$ \\
\hline
\end{tabular}

infarctions; 24 of $36(67 \%)$ of these complications occurred within seven days of the procedure and the remainder within 30 days.

\section{Discussion}

Hospital participation in the audit was $100 \%$ in East Anglia and over $85 \%$ in the North West region, and therefore the information collected in the project can be regarded as representative of upper gastrointestinal endoscopy activities within these regions. Accuracy of the data is assured by the results of the validation procedure.

The BSG recommends performing endoscopy in well designed endoscopy units, ${ }^{4}$ but over $25 \%$ of procedures are still performed at other sites. Many endoscopists work on endoscopy units that are converted wards, day units or day theatres where the staff are plagued by many problems - poor access, poor waiting areas, and poor or non-existent storage space for equipment. In particular a few units in the North West are housed in a couple of small rooms previously disused, situated off a distant corridor. Recovery areas are virtually non-existent. The BSG also recommends that two assistants, at least one of whom must be a qualified nurse (SEN or SRN), are required at each table. ${ }^{5}$ In three hospitals lists were sometimes run by one unqualified nurse. The numbers of endoscopies performed by each individual operator varied from less than 20 performed yearly to over 2000 . The BSG recommends that endoscopists should normally have a professional commitment to two or more endoscopy sessions weekly so as to acquire and maintain proficiency. ${ }^{5}$ The survey highlighted that $30 \%$ of practising consultant endoscopists (surgeons and physicians) perform less than 200 endoscopies/year. Furthermore the BSG advises that doctors should not perform diagnostic endoscopy unsupervised until they have performed a 
minimum of 200 gastroscopies; $3 \cdot 6 \%$ of the examinations included in this study were performed by unsupervised doctors who had performed less than this required figure.

\section{SEDATION AND MONITORING}

Many units now offer patients a choice of local anaesthetic spray or sedation, or both. Only $11 \%$ of patients had gastroscopy without sedation and even less $(0.9 \%)$ without local anaesthetic spray and sedation. Mean doses of benzodiazepine given were fairly uniform between regions but the range of doses was wide with some hospitals regularly recording doses of 30-40 mg diazepam and 10-15 mg midazolam. These are double the manufacturers' recommended dose ranges. ${ }^{6}$ Consultants used lower doses of benzodiazepines than trainee doctors $(5.6 \mathrm{mg}$ midazolam compared with $5.8 \mathrm{mg}$, $\mathrm{p}<0.01$, and $12.9 \mathrm{mg}$ diazepam compared with $14.2 \mathrm{mg}, \mathrm{p}<0.001$ ). These higher doses may reflect the trainees' weaker intubation skills; however, prolonged intubation times combined with higher sedation doses will increase the risk to the patient. In the elderly group doses remain dangerously high, some patients aged 90 plus having been given doses more suitable for younger patients, and again exceeding data sheet recommendations. A suggested regimen is the injection of half the dose based on body weight over 30 seconds and then to titrate to effect a further $4 \mathrm{mg} / \mathrm{min}$ (diazepam) or 2 $\mathrm{mg} / \mathrm{min}$ (midazolam).

A few endoscopists are using opioids in addition to diazepam or midazolam. Studies have shown that benzodiazepines are eight times more potent when given with an opioid such as pethidine ${ }^{7}$; because of this it is important that the opioid is given first so that the effect of the benzodiazepine can be closely monitored. Some endoscopists who use pethidine actually give more sedation than others who do not. From the audit the mean dose of pethidine used was $48 \mathrm{mg}$, although there was a wide range of doses given $(12 \cdot 5-200 \mathrm{mg})$. Pethidine should be given first at $25 \%$ of the dose reserved for sole administration, preferably up to 30 minutes beforehand so that the dose of benzodiazepine can be titrated carefully (again using $25 \%$ of the usual dose) once the pethidine has taken effect. ${ }^{8}$

There is now little doubt that arterial oxygen desaturation occurs frequently during upper gastrointestinal endoscopy. ${ }^{9-11} \mathrm{~A}$ fall in mean oxygen saturation to $90 \%$ or below is always significant; especially in the case of elderly patients or those with lung or heart disease. Routine oxygen supplementation ${ }^{12}$ may help counteract, and pulse oximetry may detect the hypoxaemia associated with sedation, but these have not been shown to be standard practice in this audit. Most of the problems occurred in patients identified as high risk (ASA 3-5), but some occurred in low risk patients, so a high level of monitoring should be the rule rather than the exception. For many endoscopists the first time they meet the patient is on the unit seconds before sedation is started and there is little time for assessment of the patient's medical condition.

In some units, despite the enthusiasm, there was a less than adequate understanding of science behind the pulse oximeter; the alarm was sometimes set at $85 \%$ or if the patients saturation was unusually low then the alarm would be set even lower! Intravenous access with an indwelling plastic cannula should be established before the procedure, and maintained until the patient has fully recovered. Most patients, however, were endoscoped without continuous intravenous access, particularly in the North West where many endoscopists favoured one injection of drugs into the ante-cubital fossa. Many in East Anglia were using butterflies, which were removed on return to the recovery area. While a butterfly permits immediate readministration of extra sedation or anticholinergic agents, if necessary, it may not remain in situ for long enough to be useful as emergency access after the procedure. ${ }^{13}$ Of the five cardiac arrests that occurred during or shortly after the procedure, four patients were endoscoped with no intravenous access. A recent report ${ }^{14}$ prepared for the Standing Dental Advisory Committee has recommended that when intravenous agents are used an indwelling needle or cannula should be used and not removed until the patient is fully recovered; whereas the BSG has so far recommended that continuous intravenous access should be used for all 'at risk' patients. ${ }^{15}$

\section{ANTICHOLINERGIC AGENTS AND LOCAL}

ANAESTHETICS

The use of anticholinergics during upper gastrointestinal endoscopy is decreasing. Recent reports have shown that anticholinergic premedication does not improve the quality of diagnostic endoscopy ${ }^{16}$ nor does it have any protective effect on the heart rhythm. ${ }^{17}$ Conversely hyoscine 22 can cause both hypotension and tachycardias. In total, eight patients experienced significant cardiac arryhthmias that required treatment, including five patients who arrested; of these, four patients had been given hyoscine 22 (two had been given doses of $40 \mathrm{mg}$ ). A recent study has also questioned the benefit of local anaesthetics ${ }^{18}$; others have queried its safety margin. Workers have shown that considerable blood concentrations have been recorded after surface anaesthesia; local anaesthetic sprayed onto a vascular membrane is absorbed as quickly as if the drug had been given intravenously. ${ }^{19}$ Lignocaine is a respiratory depressant and it can cause hypotension, bradycardia, and cardiac arrest. These effects may be potentiated by benzodiazepines. Pharyngeal anaesthesia, combined with the presence of the fibrescope, which interferes with glottic closure and swallowing, is known to cause pulmonary aspiration ${ }^{20} ; 10$ of 11 of the patients reported in the audit to have had pneumonia shortly after the procedure had received local anaesthesia $(p<0 \cdot 001)$. 
RECOVERY AND FLUMAZENIL USE

Most units send patients to recover for a minimum of one hour on adequately staffed and equipped bedded areas adjacent to the endoscopy room. In some hospitals the recovery area is some distance from the unit and in others, provision for recovery after endoscopy is inadequate. Units with inadequate staffing levels and too little space send patients to recover in an armchair (which may or may not recline) in rooms unstaffed save for an emergency bell, which the patient still drowsy and confused from sedation, is asked to ring if he or she requires attention. This room may be adjacent to the unit or at worse situated some yards down the corridor. As a result some units have a very low threshold for the use of flumazenil.

\section{COMPLICATIONS, DEATHS, AND ADVERSE} OUTCOMES OCCURRING WITHIN 30 DAYS OF ENDOSCOPY

This study is the first large prospective audit of endoscopy related deaths and complications and has included events occurring up to 30 days after endoscopy. In all, 104 patients died within this period. Some died as a result of perforation, but in many other cases such as those with pneumonia, myocardial infarct, and cerebrovascular accident, the connection with endoscopy was debatable.

There were a total of five cardiac arrests either during or shortly after the procedure. Table III shows the more serious events. All were initially successfully resuscitated but one of these died four days later from an aspiration pneumonia. Cardiorespiratory complications were reported in 31 cases, many of whom required active treatment including flumazenil and oxygen therapy. As can be seen from Table III many of the patients were elderly with ASA grades 2-4 and yet intravenous access and pulse oximetry were not invariably used. Supplemental oxygen was not given to any of these patients.

The patient who developed a cerebrovascular accident immediately after the examination and died seven days later was an 82 year old man who was ASA grade 3 . The dose of midazolam used ( $4 \mathrm{mg}$ ) caused both hypotension and hypoxia precipitating the cerebrovascular accident. A further five patients were reported to have developed cerebrovascular accidents at various times after gastroscopy of whom three died. In three cases the complication occurred within three days of the procedure and it is probable that the event was a direct consequence of the endoscopy. In addition to the five cardiac arrests there was a further one patient who developed chest pain, bradycardia, and an abnormal electrocardiogram suggestive of infarct. This 79 year old woman died at home seven days later but a postmortem examination was not performed. A further 18 patients had myocardial infarcts between one and 22 days after the procedure of which 13 died. As with the cerebrovascular accidents a causal link is suggested.
In total there were 11 cases of pneumonia, of whom eight died; two of these deaths were judged to result directly from the procedure, clearly relating to an episode of aspiration on the unit. The audit has established a clear link with local anaesthesia $(p<0.001) ; 10$ of 11 of the patients with pneumonia had been given local anaesthesia and it is probable that the other nine cases of pneumonia were related to the procedure. The use of local anaesthesia is not only implicated in causing aspiration pneumonia, but its use makes it much more probable that aspiration will go unrecognised. The eight deaths from pneumonia have been an important finding in this study and it is recommended that pneumonia complicating upper gastrointestinal endoscopy should become the focus of further study.

In a total of 36 cases of myocardial infarctions, cases of pneumonia, and cerebrovascular accidents, twice as many occurred in the first week after gastroscopy than in the second and third combined. The expected death rate from these conditions is $0.068 \%$ per month ${ }^{21}$; the death rate after gastroscopy (excluding inpatients and therapeutic gastroscopy) calculated from the audit figures is $0.116 \%$ per month. Thus the observed death rate is 1.7 times higher than expected when compared with the general population for daycase diagnostic gastroscopy.

At a conservative estimate for the 13036 patients undergoing diagnostic endoscopy without any therapeutic intervention, there was one death because of perforation, two deaths because of aspiration pneumonia, and at least one death after a cerebrovascular accident and one after myocardial infarction. A further death occurred after uncontrollable haemorrhage after biopsy of an oesophageal ulcer, and a seventh after extensive mediastinal emphysema. Thus, the death rate was estimated as at least seven of 13036 , or one in 2000 . As these figures rely on the reporting of complications by anonymous doctors, they are probably an underestimate.

The authors wish to thank Miss Chris McCourt, administrative assistant, BSG for all her help throughout the project both in its planning and organisation. Grateful thanks also extend to all those doctors and endoscopy assistants from the two regions who cooperated with the audit team.

Members of the steering group

H B Devlin, Chairman, Royal College of Surgeons; A T R Axon, British Society of Gastroenterology; G D Bell, BSG; J E Charlton, Royal College of Anaesthetists; P D Fairclough, BSG; J D Hardcastle, Royal College of Surgeons; A Hopkins, Royal College of Physicians; R J Leicester, BSG; R F McCloy, BSG; H R Matthews, The Thoracic Society of Great Britain; D Watkin, Association of Surgeons of Great Britain and Ireland; M A Quine, Research Fellow; C McCourt, Administrative Assistant (BSG); C Brizzolara, Administrative Assistant (RCS).

1 Daneshmend TK, Logan RFA, Bell GD. Sedation for upper gastrointestinal endoscopy: results of a nationwide survey. Gut 1991; 32: 12-15.

2 Arrowsmith J, Gerstman B, Fleischer D, Benjamin S. Results from the American Society for Gastrointestinal Endoscopy/ US Food and Drug Administration collaborative study on complication rates and drug use during gastrointestinal endoscopy. Gastrointest Endosc 1991; 37: 421-7.

3 Hart R, Classen C. Complications of diagnostic gastrointestinal endoscopy. Endoscopy 1990; 22: 229-33.

4 The British Society of Gastroenterology. Provision of gastrointestinal endoscopy and related services for a district gastrointestinal endoscopy and relat
general hospital. London: 1992.

5 The British Society of Gastroenterology. Report of a working party on the staffing of endoscopy units. London: 1987. 
6 ABPI. ABPI data sheet compendium. London: Datapharm Publications, 1991.

7 Ben-Shlomo I, Abd-El-Khan H, Ezry J, Zohar S, Tverskoy $M$. Midazolam acts synergistically with fentanyl for induction of anaesthesia. Br $\mathcal{F}$ Anaesth 1990; 64: 45-57.

8 Geller E. Report on workshop on drugs for sedation. In: McCloy RF, ed. Quality control in endoscopy. Berlin: Springer-Verlag, 1991: 22-9.

9 Whorwell PJ, Smith CL, Foster KJ. Arterial blood gas tensions during upper gastrointestinal endoscopy. Gut 1976; 17: 797-800.

10 Murray AW, Morran CG, Kenny GNC, Anderson JR Arterial oxygen desaturation during upper gastrointestinal
endoscopy: the effects of a midazolam/pethidine combination. Gut 1990; 31: 270-3.

11 Bell GD, Reeve PA, Moshiri M, Morden A, Coady T, Stepleton PJ, et al. Intravenous midazolam: a study of the degree of oxygen desaturation occurring during upper gastrointestinal endoscopy. Br f Clin Pharmacol 1987; 23: 703-8.

12 Bell GD, Morden A, Bown S, Coady T, Logan RFA. Prevention of hypoxaemia during upper gastrointestinal endoscopy by means of oxygen via nasal cannulae. Lancet 1987; i: $1022-3$.

13 Smith RS, Bell GD, Fulton B, Quine MA, Morden A. A comparison of winged steel needles and Teflon cannulas in maintaining intravenous access during gastrointestinal endoscopy. Gastrointest Endosc 1993; 39: 33-6.

14 General anaesthesia, sedation and resuscitation in dentistry, report of an expert working party. Standing Dental Advisory Committee of the General Dental Council, March 1990.

15 Bell GD, McCloy RF, Charlton JE, Campbell D, Dent NA Gear MWL, et al. Recommendations for the standards of sedation and patient monitoring during gastrointestinal endoscopy. Gut 1991; 32: 823-7.

16 Hedenbro JL, Frederiksen SG, Lindblom A. Anticholinergic medication in diagnostic endoscopy of the upper gastromedication in diagnostic endoscopy of the upp

17 McCloy RM, Chiti CC. ECG Changes during fibreoptic upper GI endoscopy and colonoscopy. Gastrointest Endosc 1976; 22: 231 .

18 Chuah SY, Crowson CP, Dronfield MW. Topical anaesthesia in upper gastrointestinal endoscopy. BMf 1991; 303: 695 .

19 Covino BG, Vassallo HG. Local Anaesthetics. Mechanism of action and clinical use. New York: Grune and Stratton, 1976: 99.

20 Lipper B, Simon D, Cerrone F. Pulmonary aspiration during emergency endoscopy in patients with upper gastro-
intestinal haemorrhage. Crit Care Med 1991; 19: 330-3.

21 Office of Population Censuses and Surveys. Mortality Statistics. Series DH2 no 17. London: HMSO. 